\title{
Effect of different cooking methods on glycaemic index of Indian and Pakistani basmati rice varieties
}

\author{
M D T L Gunathilaka, S Ekanayake \\ (Index words: GI, IBR, PBR, rice cooker, microwave)
}

\begin{abstract}
Introducton Glycaemic index (GI) reflects the blood glucose response after ingestion of a $50 \mathrm{~g}$ digestible carbohydrate portion. Many factors affect the $\mathrm{Gl}$, including degree of starch gelatinization.

Methods The objective was to determine the $\mathrm{Gl}$ and the effect of different cooking methods on GI of a Pakistani basmati rice (PBR) and an Indian basmati rice (IBR) frequently purchased by Sri Lankans. This was a crossover study. Participants were ten healthy individuals aged 20-30 years whose BMI range was $18.5-23.5 \mathrm{kgm}^{-2}$. Proximate composition, [carbohydrate, protein, fat, soluble dietary fibre (SDF), insoluble dietary fibre (IDF) and ash], amylose content and $\mathrm{Gl}$ of the two rice varieties were determined by using standard methods. Rice was cooked separately in a rice cooker and a microwave by adding 1 cup of rice $(110 \mathrm{~g})$ and $1 \mathrm{cup}$ of water $(150 \mathrm{ml}))$. Glucose was used as the standard. GI values were expressed as the average value of 10 participants.
\end{abstract}

Results Fat, total dietary fibre (TDF), SDF and IDF contents were significantly $(p<0.05)$ higher in IBR when compared to PBR. The GI values of IBR and PBR cooked in a rice cooker $(\mathrm{Gl}=54 \mathrm{SD}=8$; $\mathrm{GI}=64 \mathrm{SD}=12)$ or microwave $(\mathrm{Gl}=43 \mathrm{SD}=28 ; \mathrm{Gl}=56 \mathrm{SD}=12)$ belonged to low and medium $\mathrm{Gl}$ categories respectively. A percentage reduction in GI values was seen in PBR $(12.5 \%)$ and IBR $(20.4 \%)$ when cooked in a microwave oven compared to a rice cooker.

Conclusions Irrespective of the method of cooking PBR had medium $\mathrm{GI}$ and IBR had low $\mathrm{GI}$.

Ceylon Medical Journal 2015; 60: 57-61

\section{Introduction}

The GI is defined as "the incremental area under the blood glucose response curve of a $50 \mathrm{~g}$ digestible carbohydrate portion of a test food expressed as a percent of the response to the same amount of carbohydrate from a standard food taken by the same subject" [1]. Carbohydrates in foods are digested at different rates depending on several factors (amount of carbohydrate, nature of the monosaccharide components and starch, cooking or food processing and other food components). Thus, foods are categorised into low (55 or less), medium (56-69) and high (70 or above) GI foods [1].

The prevalence of obesity and type 2 diabetes is rapidly increasing in both the developed and developing countries. The prevalence of diabetes in Sri Lankan adults was $10.3 \%$ in 2005 and increased to $18.6 \%$ by 2011 [3]. The prevalence of obesity in Sri Lankan adults was 9.2\% in 2010 [4]. Consumption of more refined, fast release, staple carbohydrate foods is cited as one of the major reasons for the development of obesity and other noncommunicable diseases [5]. Thus, selection of foods and dietary modifications are important to prevent or control these conditions.

Rice is the staple food in Sri Lanka contributing to glycaemic carbohydrates and thus to the glycaemic response. Basmati is a rice variety used by Sri Lankans. Though rice is our staple food, data related to GI of some commonly consumed imported basmati varieties are not available. Thus, the present study was conducted to determine the GI and effect of two commonly used cooking methods on GI of two imported basmati varieties available in Sri Lanka.

\section{Methods}

An unstructured interview type market survey was carried out to collect information regarding the consumer purchasing trends and preferences. Following the survey, two basmati rice varieties Indian basmati rice (IBR) and Pakistan basmati rice (PBR) were selected. Rice adequate for the whole GI study ( $7 \mathrm{~kg}$ ) was purchased from a retailed shop at Battaramulla, Sri Lanka at the beginning of the study.

Two rice varieties were cooked separately in a rice cooker (Panasonic) and microwave (LG) by adding water ( 1 cup of rice $(110 \mathrm{~g})$ : 1 cup of water $(150 \mathrm{ml})$ ). Portions containing a $50 \mathrm{~g}$ digestible carbohydrate of IBR and PBR were $147 \mathrm{~g}$ and $151 \mathrm{~g}$ respectively. Coconut sambol was prepared using coconut scrapings $(150 \mathrm{~g})$, red chili pieces (2 table spoons), onions (50 g), garlic (20 g), salt powder (1 tea spoon) and lime ( 2 pieces). Coconut sambol $20 \mathrm{~g}$ was served with each serving. Length and width of the

Department of Biochemistry, Faculty of Medical Sciences, University of Sri Jayewardenepura, Nugegoda, Sri Lanka.

Correspondence: SE, e-mail: <sagarikae@hotmail.com>. Received 28 October 2014 and revised version accepted 30 March 2015. 
two rice varieties were determined and rice categorised according to their length and shape [6].

Proximate compositions of the cooked rice of two rice varieties were determined by using standard methods. Samples for proximate analyses were prepared by drying cooked rice $\left(40^{\circ} \mathrm{C}-45^{\circ} \mathrm{C}\right.$, electrical oven, $24 \mathrm{~h}$, memmert, Germany) followed by milling (25000 RPM, 230V, 50-60 $\mathrm{Hz}, 300 \mathrm{~W}$ IKA ${ }^{\mathrm{R}}$ A11 basic Brazil).

The moisture and ash contents were measured by AOAC official methods [7,8]. The digestible carbohydrate content, fat and soluble and insoluble dietary fibre contents were determined with Holm's method, Croon and Guchs and by the method of Asp et al., respectively [9,11]. The crude protein was determined by Kjeldahl method [12]. Amylose and amylopectin contents of two rice varieties were determined by Juliano method [13].

GI of the two rice varieties was determined using a standard method [14]. Determination of the GI was carried out as a cross over study. Ten apparently healthy volunteers aged 20-30 years with BMI ranging from 18.5-23.5 $\mathrm{kgm}^{-2}$ were selected. The participants were asked to refrain from smoking, drinking alcohol and to restrict vigorous physical activity the day before.

Following an overnight fast (10 hours), a finger prick capillary blood sample was obtained. Glucose was used as the standard food $(\mathrm{GI}=100)$. The test foods (PBR and IBR) and the standard food were served to the same individual on separate occasions. Each subject was served with test food containing $50 \mathrm{~g}$ available digestible carbohydrate portions to be consumed within 10-15 minutes with 250 $\mathrm{ml}$ drinking water. Glucolin (gsk Glaxo Wellcome Ceylon Ltd, Sri Lanka) that contained dextrose monohydrate was used as the standard. Glucolin $55 \mathrm{~g}$ corresponding to 50 $\mathrm{g}$ available carbohydrate was dis-solved in $250 \mathrm{ml}$ water and was consumed by the same individual on a different occasion. Capillary blood samples were collected at 30 , 45, 60, 90 and $120 \mathrm{~min}$ after the first bite of the meal. The meals were given on two different days to the same participants to allow a wash-out period.

Serum glucose concentrations were determined with a Glucose-Oxidase kit (GOD-PAP/BIOLABO-France). The GI was calculated using the mean of the individual incremental area under the curve of the test food and of the standard food (FAO, 1993). The glycaemic load (GL) values of foods were calculated $(\mathrm{GL}=\mathrm{GI}$ digestible starch perserving $(\mathrm{g}) / 100)$.

The data were analysed using the Statistical Package for Social Science (SPSS) Software (version 19) and Microsoft office Excel 2007. Chemical compositions and GI are presented as means and standard deviations. The results were analysed using independent sample t-test.

Approval for the study was obtained from the Ethics Review Committee, Faculty of Medical Sciences, University of Sri Jayewardenepura, Sri Lanka. Informed written consent was obtained from all participants prior to the study.

\section{Results}

The colour of the pericarp of both PBR and IBR was white. They belonged to the long grained and had a slender shape [15]. The proximate compositions of the two rice samples are given in table 1. Except for the digestible carbohydrate, ash and moisture, all other nutrients, such as fat, TDF, SDF and IDF were significantly higher in IBR when compared to $\mathrm{PBR}(p<0.05)$. Both rice varieties belonged to the high amylose category (IBR-25.5\% and PBR-25.1\%).

\section{Table 1. Proximate composition of PBR and IBR of cooked flour (per $100 \mathrm{~g}$ dry matter)}

\begin{tabular}{|c|c|c|}
\hline \multirow{2}{*}{$\begin{array}{l}\text { Nutrients in } 100 \mathrm{~g} \\
\text { of rice flour }\end{array}$} & PBR & IBR \\
\hline & \multicolumn{2}{|c|}{ Mean \pm SD } \\
\hline Moisture (cooked rice) & $63.0 \pm 0.5$ & $64.0 \pm 0.5$ \\
\hline Ash & $0.6 \pm 0.03$ & $0.7 \pm 0.03$ \\
\hline Digestible carbohydrate & $84.3 \pm 1.1$ & $81.7 \pm 3.0$ \\
\hline Protein & 9.4 & 9.9 \\
\hline Fat & $1.4 \pm 0.13 *$ & $1.5 \pm 0.06^{*}$ \\
\hline TDF & $2.9 \pm 0.13 *$ & $4.0 \pm 0.04 *$ \\
\hline SDF & $1.5 \pm 0.02 *$ & $2.3 \pm 0.05^{*}$ \\
\hline IDF & $1.3 \pm 0.13^{*}$ & $1.7 \pm 0.05^{*}$ \\
\hline
\end{tabular}

$\mathrm{n}=6$ (except for protein, $\mathrm{n}=2$ ); SD:-Standard Deviation; *Significant differences at $95 \%$ confidence interval.

The mean peak blood glucose concentrations of PBR and IBRcooked in a rice cooker and microwave oven are given in figures 1 and 2 . The percentage reduction of peak blood glucose concentration for PBR cooked in a rice cooker was $19 \%$ and microwave oven was $20.4 \%$ compared to glucose. The peak was at 30 minutes for PBR cooked in the microwave and at 45 minutes when the sample was cooked in a rice cooker (Figure 1). The GI of PBR cooked in rice cooker as well as microwave were in the medium GI category.

The percentage reduction of peak blood glucose concentration for IBR cooked in a rice cooker was $23 \%$ and for microwave oven was $24.3 \%$ when compared to glucose. However, peak was obtained at 30 minutes for both microwave cooked and rice cooker cooked IBR samples (Figure 2). When considering the IBR, both cooking methods elicited low GI values (Table 2).

Significant differences were observed between the GI values of two rice varieties when using the same cooking method $(p<0.05)$. For each rice variety the GI values did 


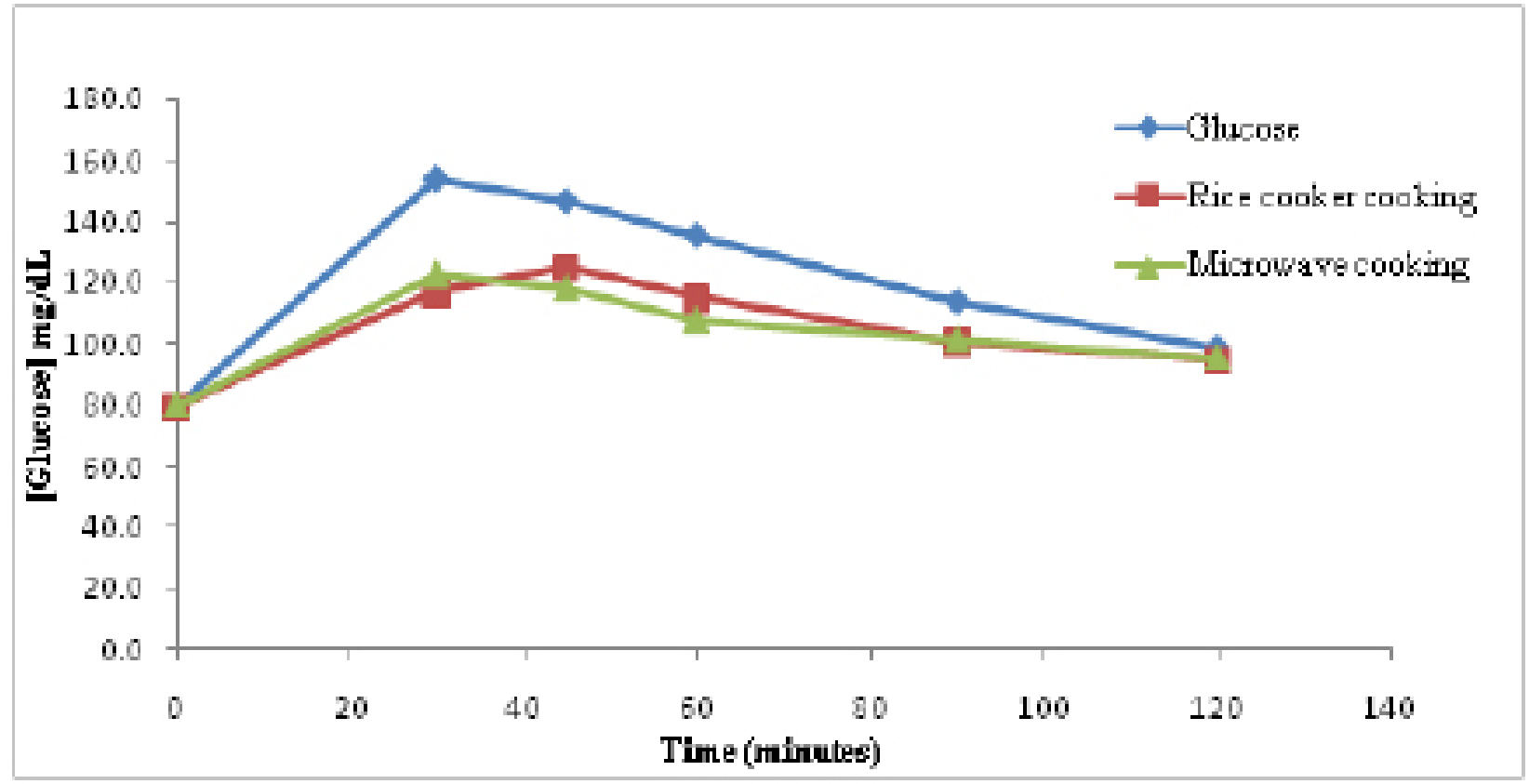

Figure 1. Glycaemic responses of glucose and PBR variety cooked in a rice cooker and microwave oven.

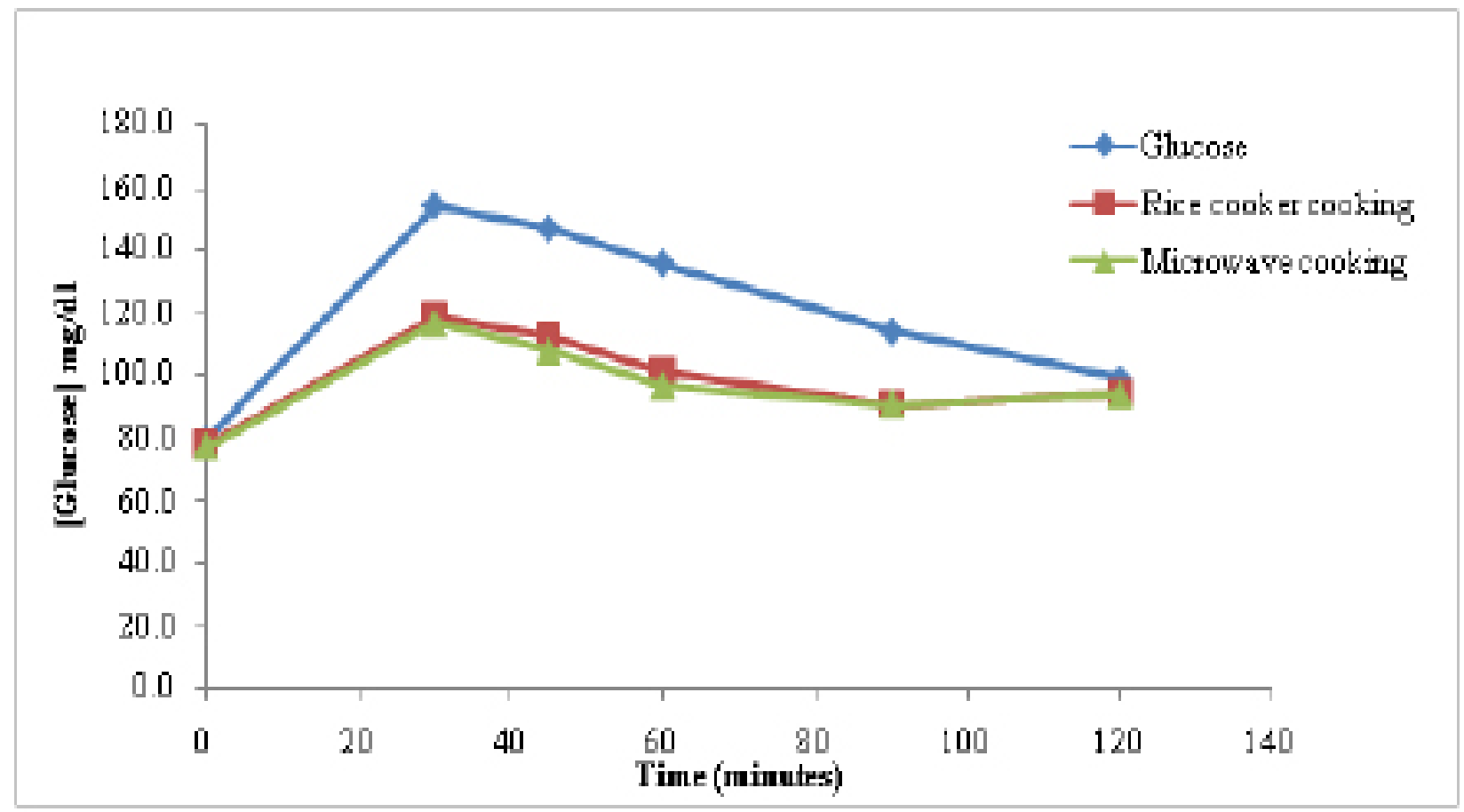

Figure 2. Glycaemic responses of glucose and IBR variety cooked in a rice cooker and microwave oven.

not significantly differ according to the cooking method $(p>0.05)$. However, microwave cooking compared to cooking in a rice cooker showed a percentage reduction of $12.5 \%$ for PBR and $20.4 \%$ for IBR. The glycaemic load (GL) of both rice varieties cooked in the rice cooker and

Vol. 60, No. 2, June 2015 microwave were in the high GI category $(>20)$. However, the GI value of IBR when cooked in a microwave $(\mathrm{GL}=22)$ was lower than the others.

\section{Discussion}


Table 2. Glycaemic indices of PBR and IBR cooked in a rice cooker and a microwave

\begin{tabular}{lcccc}
\hline & $\begin{array}{c}\text { PBR cooked in } \\
\text { a rice cooker }\end{array}$ & $\begin{array}{c}\text { PBR cooked in } \\
\text { a microwave }\end{array}$ & $\begin{array}{c}\text { IBR cooked } \\
\text { in a rice cooker }\end{array}$ & $\begin{array}{c}\text { IBR cooked } \\
\text { in a microwave }\end{array}$ \\
\hline $\begin{array}{l}\text { Mean GI ( } \pm \text { SD) } \\
\text { Peaking time }\end{array}$ & $64 \pm 12$ & $56 \pm 14$ & $54 \pm 8$ & $43 \pm 6$ \\
$\begin{array}{l}\text { Peak reduction } \\
\text { (against glucose) }\end{array}$ & 45 minutes & 30 minutes & 30 minutes & 30 minutes \\
$\begin{array}{l}\text { Reduction in GI } \\
\text { compared to rice cooker }\end{array}$ & - & $20.4 \%$ & $23 \%$ & $24.3 \%$ \\
Glycaemic load & 32 & $12.5 \%$ & - & $20.4 \%$ \\
$*_{\mathrm{n}=10}$ & & 28 & 27 & 22 \\
\hline
\end{tabular}

Different rice varieties cultivated in different geographical regions may affect the physical and chemical properties of the rice grain which will contribute to different GI values [16]. Different cooking methods also can affect the GI [17]. During cooking, heat and water soften the hard compact starch granules causing these to imbibe water, swell and eventually rupture. As a result of this, individual amylose and amylopectin molecules are released leading to gelatinisation. This makes starch more bio-available for enzymic action leading to increased glucose absorption. Thus, physical-chemical properties of starch and degree of starch gelatinisation influence the glycae-mic response and the GI of a food [17].

GI of IBR cooked in a rice cooker and microwave were in the low GI category. It has been reported that the GI of an Indian basmati rice variety cooked in an electric cooker elicited low GI, which is compatible with our data [18]. The GI of the PBR cooked in a rice cooker and microwave were in the medium GI category. The data are comparable with previous findings where the GI of four basmati rice varieties were in the medium GI category [19].

According to available data, red raw (80), white raw (81), red basmati (73) and white basmati (73) elicited high GI while keeri samba (66) belonged to medium GI category [20]. However, parboiled nadu (40) available in the Sri Lankan market showed a lower GI compared to IBR and PBR [20]. Thus, among all varieties, IBR and parboiled nadu elicited the lowest GI.

Portion sizes containing $50 \mathrm{~g}$ digestible carbohydrate of IBR and PBR were $147 \mathrm{~g}$ and $151 \mathrm{~g}$ respectively. All the female participants reported the portion size to be adequate whereas the males found the portion size to be inadequate. Thus, GL of both rice varieties cooked in the rice cooker and microwave were in the high GL category $(>20)$ when considering the actual portion size consumed.

In this study, rice was given with $20 \mathrm{~g}$ of coconut sambol which consists of carbohydrate, protein, fat and dietary fibre (Table 3) [21]. There is a negative relationship for both fat and protein with GI [1]. However, their effect on GI is not seen unless relatively large quantities of nutrients (about $30 \mathrm{~g}$ of protein and $50 \mathrm{~g}$ of fat per 50 $\mathrm{g}$ carbohydrate portion) are added to a meal [22]. Thus, when considering the present study, effect of nutrients contributed by coconut sambol for GI can be considered negligible. Also the effect of dietary fibre from coconut sambol affected both rice meals evenly.

In conclusion PBR showed medium GI values and IBR showed low GI values when cooked in either a rice cooker or a microwave.

\section{Conflicts of interest}

Table 3. Nutritional values per $100 \mathrm{~g}$ of fresh coconut

\begin{tabular}{lc}
\hline \multicolumn{1}{c}{ Nutrient } & per $100 \mathrm{~g}$ \\
\hline Carbohydrate & $15.23 \mathrm{~g}$ \\
Protein & $3.3 \mathrm{~g}$ \\
Total Fat & $33.49 \mathrm{~g}$ \\
Cholesterol & - \\
Total dietary fibre & $9 \mathrm{~g}$ \\
\hline
\end{tabular}

Data extracted from USDA National Nutrient Database (2013)

We declare that there are no conflicts of interest.

\section{References}

1. Wolever TMS, Jenkins DJA, Jenkins AL, Josse RG. The glycemic index: methodology and clinical implications. $\mathrm{Am}$ J Clin Nutr 1991; 54: 846-54.

2. Katulanda P, Constantine GR, Mahesh JG, et al. Prevalence and projections of diabetes and pre diabetes in adults in Sri Lanka. Diabet Med 2008; 25:1062-9.

3. Katulanda P, Rathnapala DAV, Sheriff R, Matthews DR. Province and ethnic specific prevalence of diabetes among Sri Lankan adults. Sri Lanka Diabetes Endocrinol Metabol 2011; 1: 2-7. 
4. Katulanda, P, Jayewardene MA, Sheriff MH. Constantine GR and Matthews DR. Prevalence of overweight and obesity in Sri Lankan adults. Obes Rev 2010; 11: 751-6.

5. Jayawardena R, Swaminathan S, Byrne NB, Soares MJ, Katulanda, P, Hills AP. Development of a food frequency questionnaire for Sri Lankan adults. Nutr J 2012; 11: 2-6.

6. Guzman JD, Peralta EK. Classification of Philippine rice grains using machine vision and artificial neural networks. World Conference on Agricultural Information and IT 2008; 6: 41-8.

7. Association of Official Analytical Chemists. Official Methods of Analysis of the AOAC. $14^{\text {th }}$ ed.; AOAC: 1984a; Washington DC, 14.004 .

8. Association of Official Analytical Chemists. Official Methods of Analysis of the AOAC. 14 ${ }^{\text {th }}$ ed.; AOAC 1984b; Washington DC, 7.009.

9. Holm J, Drews A and Asp NG. A rapid method for the analysis of starch. Starch/Starke 1986; 38, 224-6.

10. Croon LB and Guchs G. Setthaltsbestamning I mgolochmjolprodketer. (Crude fat analysis of different flours and flour products). VarFoda 1980; 32, 425-7.

11. Asp NG, Hallmer H, Siljestrom M. Rapid enzymatic assay of insoluble and soluble dietary fibre. Journal of Agriculture and Food Chemistry 1983; 31, 476-8.

12. Association of Official Analytical Chemists. Official Methods of Analysis of the AOAC; AOAC 1987; Washington DC, 7.033 .

13. Juliano BO. Simplified assay for milled rice amylose. Cereal Science Today 1971; 16: 334-8.

14. Wolever TM, Vorster HH, Bjorck, Miller JB, Brighenti, F, Mann JI, et al. 2003. Determination of the glycaemic index of foods: interlaboratory study. Eur J Clin Nutr 2003; 57: 475-82.

15. Food and Agricultural Organization. Physical grain characteristics of paddy/milled rice and its grades and standards. 1992; United Nation: FAO.

16. Food and Agricultural Organization, 1993. Rice in human nutrition. United Nation: United Nation: FAO.

17. Leonora NP, Lilian UT, Bienvenido OJ, Consuelo MP, Suk $\mathrm{HY}$ and Gordon RG. Rice varieties with similar amylose content differ in starch digestibility and glycaemic response in humans. Am J Clin Nutr 1991; 54: 871-7.

18. Srinivasa D, Raman A, Meena P, Chitale G, Marwaha A, Jainani KJ. Glycaemic Index (GI) of an Indian Branded Thermally Treated Basmati Rice Variety: A Multi Centric Study. Association Physicians India 2013; 61: 32-6.

19. Henry CJK, Helen JL, Caroline MS, Hamish R, Simon H. Glycaemic index and glycaemic load values of commercially available products in the UK. Br J Nutr 2005; 94: 922-30.

20. Ekanayake S, 2013. Glycaemic indices (GI) and factors affecting the GI of Sri Lankan foods. SLMA News letter 6 : 4-8.

21. TemaNord. Glycaemic Index: From Research to Nutrition Recommendations? 2005; Nordic Council of Ministers, Copenhagen.

22. USDA National Nutrient Database. Nutrient values and weights are for edible portion of Nuts, coconut meat, raw. United States 2013; Available at: http://ndb.nal.usda.gov/ ndb/foods/show/3700 [Accessed on 15/07/2014]. 